\title{
FONTES FRANCISCANAS: OS FRANCISCANOS NA HISTORIOGRAFIA DO BRASIL E NA HISTÓRIA DA EDUCAÇÃO BRASILEIRA
}

\author{
Tania Conceição Iglesias ${ }^{1}$
}

taniglesias@yahoo.com.br

\section{RESUMO}

artigo de divulgação de fontes documentais e bibliográficas que abordam a ação missionária da Ordem franciscana no Brasil Colonial (1500-1822) decorrente de investigações desenvolvidas entre 2005 a $2010^{2}$. Este texto é o terceiro da série de um projeto de três publicações sobre o assunto. No primeiro artigo foram apresentadas as obras Clássicas da Ordem franciscana. No segundo artigo foram apresentadas as fontes bibliográficas da historiografia franciscana no Brasil Colonial, bem como, uma análise dos temas por ela abordados. Este, o último da série, apresenta as obras da Historiografia do Brasil que abordam o tema franciscano e, as produções historiográficas brasileiras sobre a história da educação franciscana.

Palavras-chave: Fontes Documentais, Brasil, Educação Colonial, franciscanos, Historiografia.

\section{FRANCISCAN SOURCES: THE FRANCISCANS IN HISTORIOGRAPHY OF BRAZIL AND THE HISTORY OF BRAZILIAN EDUCATION}

\begin{abstract}
This article deals with the disclosure of documentary and bibliographic sources that refer to the missionary action of the franciscan Order in colonial Brazil (1500-1822), resulting from the investigations which were developed between 2005 to 2010 . This text is the third of a series of the three publications about the franciscan sources. In the first article we presented the Classical works of the franciscan Order. In the second paper we presented the bibliographical sources of the franciscan historiography in Brazil colonial as well as a historiographical analysis of the containable issues inside of this historiography. This is the last one of the series that shows the works of the Historiography of Brazil which refer to the franciscan theme, and the Brazilian historiographical productions about the history of the franciscan education.
\end{abstract}

Keywords: Documentary Sources, Brazil, Colonial Education, Franciscan Historiography

Este texto, baseado nos estudo e pesquisas desenvolvidas no processo de elaboração da tese doutoral intitulada: A Experiência Educativa da Ordem Franciscana: aplicação na América e sua influência no Brasil Colonial é o terceiro da série de artigos de divulgação das fontes documentais e bibliográficas brasileiras sobre a ação missionária dos franciscanos no Período Colonial ${ }^{3}$. O presente tem o objetivo de dar prosseguimento na divulgação dessas produções e documentos, tendo em vista contribuir para a divulgação do assunto nos meios acadêmicos, bem como, acrescentar este estudo à tênue produção existente. No primeiro artigo foram apresentadas as obras Clássicas da Ordem, priorizando as Crônicas mais antigas, que por seu valor histórico, são consideradas fontes documentais, 
oferecendo uma pequena resenha da principal Crônica franciscana no Brasil. No segundo artigo foram apresentadas as fontes bibliográficas, que são as produções específicas da ação missionária na historiografia franciscana brasileira, oferecendo uma análise dos temas por elas abordados. Este, o último da série, apresenta as obras da Historiografia do Brasil que abordam o tema franciscano e, as produções historiográficas brasileiras sobre a história da educação colonial franciscana. O trabalho, que tem como base pesquisa realizada no Brasil, respeitará a ordem cronológica em que essas fontes bibliográficas foram produzidas.

Os Franciscanos, embora militantes na obra missionária da história do Brasil, foram muito pouco notados pelos historiadores brasileiros. Da parcimoniosa produção sobre a ação dos Freis de São Francisco de Assis nestas terras, a maioria é vinculada a historiadores membros da Ordem. Excetuando alguns escritores como Gilberto Freyre e José Honório Rodrigues, são poucas as produções bibliográficas clássicas sobre a História do Brasil que lembram a presença da Ordem franciscana na constituição do país.

\section{FRANCISCANOS NA HISTORIOGRAFIA BRASILEIRA}

Seguramente, o único autor clássico da historiografia brasileira que dedicou um estudo à Ordem Franciscana foi Gilberto Freyre, que escreveu o livro intitulado "A Propósito dos Frades: sugestões em torno da influência de religiosos de São Francisco e de outras Ordens sobre o desenvolvimento de modernas civilizações cristãs, especialmente das hispânicas nos trópicos", publicado em Salvador pela Editora Aguiar \& Souza em 1959.

O livro, que apresenta conferências e ensaios sobre temas franciscanos motivados pelas comemorações da fundação do Convento do Recife e da restauração da Província franciscana do Norte do Brasil, realizadas, respectivamente, em 1956 e 1957, possui textos inéditos de Freyre, que também o prefacia e para quem a influência dos frades, cuja simplicidade de vida nunca significou simplismo de idéias, não deve ser esquecida, nomeadamente em função da análise das influências culturais da filosofia franciscana. Segundo ele, tais influências foram:

[...] inspiradoras de indagações e de experimentos científicos e desenvolvidas, desde anos remotos, em Oxford e em Paris, por frades de São Francisco que foram também, além de homens bons, grandes mestres ou doutôres: tão grandes que a influência das suas idéias transbordou da época em que atuaram em universidades e em claustros para se prolongar por outras épocas e noutros centros de estudo e de ação, numa verdadeira sucessão de ondas renovadoras do pensamento e da cultura dos europeus e de cristãos. (FREYRE, 1959, p. 9)

O autor sustenta seu argumento com a obra de Lewis Hanke:

E o professor Lewis Hanke já mostrou, em livro publicado em 1935 pela Universidade de Harvard - The First Social Experiments in América - que o primeiro inquérito em tôrno da inteligência e das aptidões de ameríndios, executou-no, por ordem de Madri, frades espanhóis, muito antes que na América Inglesa começassem a florescer universidades; e que dentro dessas universidades se esboçasse qualquer comêço de

Revista HISTEDBR On-line, Campinas, n.43, p. 254-267, set2011 - ISSN: 1676-2584 255 
antropologia experimental. (FREYRE, 1959, p. 11)

No prefácio da obra, Freyre já ressalta importantes acontecimentos marcados pela ação dos frades franciscanos para o desenvolvimento cultural brasileiro.

Particularmente na parte do Brasil - a setentrional - cuja cultura tem irradiado dêsses dois velhos centros de estudos e de ação, hoje universitários, outrora monacais, no modo de exercerem sua atividade intelectual e sua influência educativa: o Recife e Salvador da Bahia. Tão monacais que a Faculdade de Direito do Recife - núcleo da Universidade - nasceu num Convento de Olinda; e a Faculdade de Medicina da Bahia ainda hoje tem sua sede num quase canônico Terreiro de Jesus, enobrecido pela ciência dos médicos depois de ter sido ilustrado pelo saber dos clérigos. (FREYRE, 1959, p. 11)

A obra afiança as idéias que estavam sendo desenvolvidas pelo autor a respeito da influência da experiência nominalista das atividades européias dos frades franciscanos sobre as novas civilizações. Gilberto Freyre denominou esses estudos de tropicologia, ou, no caso específico, hispano-tropicologia. Este seria um ramo do saber que se adaptaria a cada país colonizador, conforme a maneira como ele agiu durante a colonização, em relação aos traços culturais internalizados pela reação dos colonizados. Além dessa obra, Freyre publicou em uma edição comemorativa do tricentenário da Província Franciscana de Santo Antonio do Brasil, v. I, 1957, conjuntamente outros autores, o discurso intitulado: Em Torno do Esforço Franciscano no Brasil. Nos argumentos fortemente embasados desse discurso, se encontram informações preciosas para o estudioso da história Brasileira.

Não obstante se trate de tema já discutido pelos cronistas franciscanos, a obra de Gilberto Freyre é relevante para pesquisadores do franciscanismo no Brasil não só por ter sido escrita e organizada por um autor clássico da sociologia e da historiografia brasileira, de alta erudição e reconhecimento, mas também, por não ter sido escrita por um franciscano, conferindo-lhe isenção de qualquer forma de proselitismo e riqueza no detalhamento das informações oferecidas.

Interessante ressaltar que, das produções históricas consultadas que se referem aos franciscanos no Brasil Colonial, as que mais se dedicaram ao tema foram escritas por autores estrangeiros. Destacam-se as seguintes obras: "Introdução à História das Bandeiras", do português Jaime Cortesão, e uma dissertação de mestrado da Universidade de Lisboa intitulada "Missão e Cultura dos Franciscanos no estado do Maranhão e GrãoPará, século XVII: ao serviço de Deus, de sua Majestade e bem das almas", escrita por Maria Adelina de Figueira Batista Amorim.

Também é preciso destacar bons trabalhos que vêm sendo desenvolvidos, principalmente nos cursos de Pós-graduação, que, apesar de não se dedicarem diretamente à história dos franciscanos, abordam a questão de forma mais aprofundada do que a maioria dos livros clássicos da história do Brasil. Têm-se, por exemplo, as teses de doutorado: "Colonização, catequese e educação no Grão-Pará", de Anselmo Alencar Colares (2003) e "Formas de Representação Religiosa no Brasil e no México do Século XVI", de Leandro Karnal (1998).

Quem escreveu sobre a ação missionária dos franciscanos no Período Colonial, considerando-a como um elemento importante para a compreensão do desenvolvimento do Brasil foram os autores que, de forma mais ampla, tomaram o contexto Colonial como expansão européia da qual fizeram parte não só Portugal, como também outros países, com

Revista HISTEDBR On-line, Campinas, n.43, p. 254-267, set2011 - ISSN: 1676-2584 256 
destaque para a participação da Espanha e da Ordem franciscana espanhola no empreendimento colonizador não só do Brasil, como de toda a América.

Nesse sentido, foi publicada em 2005 uma importante obra sobre o Período Colonial a respeito da formação do estado de Santa Catarina, que, na ocasião, pelo tratado de Tordesilhas, fazia parte das possessões da Espanha ${ }^{4}$.

A obra "Expedições: Santa Catarina na Era dos Descobrimentos Geográficos: 15011600 ", publicada em três volumes luxuosamente encadernados teve uma tiragem inicial de 1500 exemplares. Ela é resultado de quinze anos de pesquisa do historiador Amílcar D'Avila de Mello (2005) ${ }^{5}$ em Arquivos e Instituições no país e no exterior, entre os quais o Arquivo Geral das Índias em Sevilha, a Biblioteca Britânica de Londres, a Biblioteca Widener da Universidade de Harvard. O livro, que teve sua publicação financiada pela Petrobrás, ainda não está à venda, mas nos foi gentilmente cedido pelo autor. Amílcar faz questão de ressaltar que, muito embora a obra siga os rigores acadêmicos, foi elaborada à margem da academia e com recursos próprios.

Em entrevista fornecida à "República do Livro", ele justifica o seu trabalho quando afirma:

Havia uma imensa lacuna nas fontes documentais e historiográficas da Santa Catarina quinhentista que precisava ser preenchida. A base da história oficial brasileira que trata desse período foi obra de estudiosos do século XIX e das primeiras décadas do XX, época em que ainda estavam se consolidando as fronteiras com os vizinhos platinos. A produção desses historiadores estava, na maioria das vezes, a serviço da diplomacia luso-brasileira. Portanto, contar a história do Brasil meridional vinculado à América espanhola significava contrariar os interesses geopolíticos da nossa nascente Nação. (MELLO, 2006) 6

É uma inestimável fonte de consulta sobre a colonização na Bacia do Rio da Prata então vinculada à América espanhola e que fornece importantes fontes documentais primárias a respeito da ação missionária da Ordem franciscana naquela região durante o período. Interessa, principalmente, a referência que o autor faz, por meio de vários documentos e crônicas quinhentistas, à experiência de frades franciscanos espanhóis que se estabeleceram em Santa Catarina em 1538 onde teriam fundado duas escolas ${ }^{7}$. Inclusive, quer se destacar que essa obra é a que fornece a maior quantidade de fontes documentais sobre Bernardo de Armenta encontrada na bibliografia brasileira.

A experiência de catequese Colonial brasileira praticada por frei Bernardo de Armenta foi citada por muitos autores franciscanos e atestada pelo jesuíta Manuel da Nóbrega. ${ }^{8}$ Segundo Sofhia Lyra,

Nóbrega em suas "cartas" atesta a existência de franciscanos entre os carijós "dois Clérigos que têm convertido e batizado muitos". Frei Adulfo Van Der Vat chamou a Missão de Mbyaçá de "uma espécie de redução protótipo das que mais tarde, em maior escala realizaram os jesuítas no Paraguai e no território das Missões. [...] Para Frei Venâncio Willeke "A Ordem de São Francisco, até 1549, foi a única a missionar no Brasil, mandou outras levas apostólicas tanto de Portugal e Espanha como da Itália para vários pontos do país, constando já em 1543 as escolas e internatos de Mbyaçá (Santa Catarina), sob a orientação de Frei Bernardo de Armenta e Frei Alonso Lebron; e até o presente nunca deixou essa Ordem Seráfica de catequizar os filhos da selva e de plantar a fé na Terra

Revista HISTEDBR On-line, Campinas, n.43, p. 254-267, set2011 - ISSN: 1676-2584 257 
de Santa Cruz". (1978, p.44)

Entretanto, em nenhuma bibliografia brasileira, encontrou-se a abundância de informações e fontes primárias até então desconhecidas e agora propiciadas pelo trabalho do historiador Amílcar D'Avila de Mello. Sua obra apresenta duas cartas e uma missiva escritas pelo frei Bernardo de Armenta, superior dos religiosos franciscanos que vieram ao Brasil na Expedição de Alonso Cabrera ao Rio da Prata, em 1538. Até então, pelo levantamento bibliográfico realizado, só havia conhecimento de uma dessas cartas, publicada por Lucas Wading, organizador e compilador de documentos franciscanos na obra Annales Minorum de 1736, volume XVI, da qual se possui uma cópia. A preciosidade dos documentos propiciados por Mello está nas informações que permitem considerar os frades franciscanos Bernardo de Armenta e seus companheiros como os primeiros missionários a desenvolverem no Brasil, de forma organizada, a experiência de catequese e, conseqüentemente, uma educação para índios.

A referida experiência e os documentos foram fundamentais para o trabalho do autor sobre o início do povoamento em Santa Catarina, já que Laguna, local onde frei Bernardo de Armenta estabeleceu a missão, era passagem obrigatória dos navegantes que, em algumas ocasiões, tiveram contato com eles, o que foi relatado por cronistas quinhentistas.

Desde o volume I, que ele denominou "Exploração e Conquista: 1501-1542", Amílcar D'Avila de Mello mostra a colonização Espanhola na América e já fornece notícias da presença dos frades franciscanos espanhóis na região do rio da Prata. No volume II, intitulado "Colonização e Abandono: 1550-1658", como o próprio nome sugere, ele escreveu sobre a decadência e o fracasso da colonização espanhola em Santa Catarina. O volume III, intitulado "Crônicas das Origens", é um verdadeiro presente para aqueles que se dedicam ao estudo da História dos franciscanos no Brasil e à história da colonização espanhola no Brasil, pois foi concebido, segundo o autor, para "preencher a lacuna que existe nas fontes primárias da historiografia quinhentista de Santa Catarina" (MELLO, p.38, v. III). Nesse último volume o autor oferece documentos e relatos de 52 cronistas quinhentistas, que constituem uma verdadeira preciosidade para os historiadores em geral, mas muito particularmente para os historiadores franciscanos, devido à publicação de documentos que relatam a obra missionária dos frades franciscanos espanhóis que, até então, eram desconhecidos.

As fontes consultadas, muitas delas traduzidas à língua portuguesa pela primeira vez, são, além de crônicas propriamente ditas, cartas régias, diplomáticas e privadas, diários de bordo, relatórios, petições, inquéritos e depoimentos de testemunhas envolvidas em litígios. A primorosa seleção desses personagens, de suas impressões e de outros documentos a eles associados pretende recuperar a memória sobre a formação dessa importante região. Com isso oferecemos ao leitor a oportunidade de conhecer e pôr em perspectiva a fascinante história colonial de Santa Catarina, narrada pelos seus protagonistas. (MELLO, 2005, p. 38)

Apesar de dedicado à história de Santa Catarina, o livro proporciona, ao reconstituir o contexto, a interação entre o mundo lusitano e o hispânico, que foi o Brasil Colonial, trazendo à tona uma questão que se considera extremamente relevante para o campo da historiografia brasileira e com a qual também compactua o autor: 
[...] Salvo honrosas exceções, os pesquisadores da História Colonial brasileira têm dado continuidade à historiografia tradicional, ou seja, omitem ou tratam superficialmente dos temas referentes à presença espanhola na região Sul. Há, também, desconhecimento da história do Rio da Prata, o que inviabiliza o amplo entendimento da conjuntura em que se insere a Santa Catarina do século XVI. (MELLO, 2006, p. 38)

Acredita-se que não é possível compreender o Brasil Colonial, tomando para a análise somente o elemento lusitano, pelo menos quando se trata de pesquisar a Ordem Franciscana no Brasil, porque os frades franciscanos que aportaram nessas terras nos primeiros tempos coloniais eram provenientes da Espanha e estavam a seu serviço.

Dessa forma, a obra de Amílcar D’Avila de Mello é a mais recente referência sobre os franciscanos no Brasil Colonial. Tal obra oferece grande contribuição, não só pela farta documentação que compila, mas também por lançar luzes sobre o tema. Percebe-se, pela revisão de literatura, que este é um campo carente de respostas pela historiografia Colonial brasileira em relação à colonização espanhola no Brasil, bem como no que se refere à Ordem religiosa franciscana.

A questão já há muito levantada por Gilberto Freyre sobre a consideração da colonização hispânica como importante elemento para a compreensão da formação cultural brasileira e, conseqüentemente para a formação do seu campo educacional, fica cada vez mais evidenciada. Não se pode mais prescindi-las das análises a respeito da obra missionária e catequética aqui desenvolvida durante o Período Colonial. Do mesmo modo, deve-se considerar o trabalho desenvolvido por todas as Ordens religiosas presentes no período, seja ela franciscana, jesuítica, dominicana, mercedária ou outras mais, que porventura aqui tenham se dedicado à educação.

Luis Fernando Conde Sangenis ${ }^{9}$ é autor do mais recente livro publicado sobre os franciscanos no Brasil, editado em 2006, pela Editora Vozes, Petrópolis e intitulado "Gênese do Pensamento único em Educação". Sua produção será classificada nas duas categorias estabelecida para essa apresentação. Não obstante ter escrito sobre a história da educação dos franciscanos no Brasil, que será tratado em item específico deste trabalho, a análise desenvolvida sobre a historiografia brasileira em relação à Ordem franciscana no Brasil permite considerá-la também como historiografia brasileira no Período Colonial.

Nessa análise o autor destaca os litígios freqüentes entre as ordens religiosas no Brasil Colonial como determinantes do caráter apologético das narrativas e crônicas. Ele discerne nela a atitude de autores religiosos da época, que exaltavam os métodos e a qualidade dos confrades, silenciando e diminuindo erros cometidos, enquanto apontavam os defeitos e erros dos adversários. Acredita que a deficiência nas análises documentais desenvolvida por historiadores subseqüentes, somada à boa organização dos jesuítas em relação à sistematização da sua história e, em contraposição aos franciscanos, que não se preocuparam em documentar e nem mesmo preservar suas fontes documentais, se constituem os agentes da manutenção da hegemonia dos jesuítas. Para Sangenis, a hegemonia jesuítica fora construída pelo relevante embate travado no campo ideológico entre as Ordens religiosas que atuaram no Brasil no Período Colonial e, permaneceu perpetuada na historiografia brasileira.

Avaliando como a história dos franciscanos se apresenta na historiografia do Brasil, o autor assinala alguns elementos ocultados, inclusive pela história eclesiástica, em relação à atividade da Ordem. Esses elementos são transformado por ele em categorias que ele utiliza para a análise do silenciamento sobre a ação missionária e catequética da Ordem 
franciscana no Período Colonial. São elas: as imprecisões, os preconceitos e as omissões que se encontram nessas obras.

$\mathrm{Na}$ categoria imprecisões, elenca autores tanto do campo religioso como do científico, e aponta várias obras ${ }^{10}$. De acordo com ele, isso pode ter ocorrido por falta de conhecimento, informação e pesquisa sobre as peculiaridades da Ordem franciscana, pois os referidos escritores cometeram confusões e equívocos que vêm sendo reproduzidos sem maiores cuidados, principalmente quando se trata das Missões franciscanas no Maranhão. Ressalta que se conhece menos do que devia sobre a história do Maranhão e do Grão-Pará e que isso se agrava quando se trata da história dos franciscanos naquele espaço.

Sangenis elenca várias obras na categoria por ele denominada preconceitos e omissões sobre os franciscanos encontrados na literatura ${ }^{11}$ e assinala:

Enquanto as imprecisões talvez se justifiquem pela falta de informação sobre a matéria tão complexa, os preconceitos e as omissões são devido às paixões que tolheram o espírito crítico de autores de crônicas, relatos, cartas e demais documentos de época, assim como dos pesquisadores contemporâneos. Não foram poucas em que se rotulou a atuação franciscana no Brasil como ineficaz, escravagista, cerceadora da liberdade dos índios, antijesuítica, pró-colonial (SANGENIS, 2006, p. 66)

O diagnóstico do autor a respeito das omissões, que também designa de esquecimentos, não é exaustivo. O autor se detém mais na análise dos preconceitos, remetendo-os à parcialidade dos escritores no tratamento da questão. Para isso, tomou as asserções desabonatórias sobre os franciscanos encontradas nas bibliografias e as analisou em confronto com as fontes documentais da época, chegando à seguinte conclusão:

[...] Apenas refletem a má vontade dos autores de aprofundar seus estudos em direção ao que ultrapasse a Companhia de Jesus, seja para falar bem quanto mal. É como se bastasse a referência aos jesuítas, tratados como representantes máximos da ação missionária e protótipos dos missionários, para dar conta do capítulo que sempre deve tematizar a catequese dos índios e dos colonos. Em geral, nos textos didáticos, o exemplo jesuítico é considerado suficiente, não havendo motivo para tratar das demais ordens religiosas, sem incorrer em "redundâncias" de um texto que deve cobrir ainda tantas outras coisas. (SANGENIS, 2006, p.70)

Apesar de defender a relevância da ação dos missionários franciscanos no Período Colonial, o trabalho não apresenta caráter antijesuítico; trata-se, antes, de crítica à historiografia brasileira, no que concerne a pouca referência feita à atividade missionária de outras ordens no quadro Colonial. Entende que o fato teve origem na imprensa escrita, por meio da capacidade que os jesuítas tiveram de utilizá-la e, perpetuou-se pelo mesmo meio nos trabalhos que não atentaram para esse fato.

O trabalho de Sangenis constitui referência importante aos pesquisadores da história franciscana, uma vez que oferece análise baseada na documentação utilizada para contrastar com a historiografia produzida não só no Brasil, como também no exterior. Quanto a esta última, merecem destaque as seguintes obras: "Introdução à História das Bandeiras" e "Os Descobrimentos Portugueses", escritas e publicadas em Portugal por 
Jaime Cortesão; "História do Brasil", publicada na França por Bartolomé Bennassar e Richard Marin, traduzida e publicada em Portugal em 2000; e a minuciosa dissertação de mestrado em História da Cultura do Brasil, da Universidade de Lisboa, defendida em 1997, por Maria Adelina de Figueiredo Batista Amorim, intitulada "Missão e Cultura dos Franciscanos no Estado do Maranhão e Grão-Pará, século XVII - ao serviço de Deus, de sua majestade e bem das almas".

Nesse sentido, pode-se afirmar que o referido livro é um relevante trabalho elaborado atualmente e oferece uma boa análise da literatura histórica em relação ao registro da ação missionária dos franciscanos no Brasil. Entretanto, a ele se quer acrescentar outros importantes autores e obras clássicas da historiografia Colonial brasileira, que são citadas por historiadores contemporâneos e que poderiam ser enquadradas nas Categorias elaboradas por Sangenis, principalmente a que ele denomina esquecimento, no que diz respeito à obra missionária dos franciscanos no Brasil. Entre elas, quer-se destacar: "História Geral do Brasil", de Francisco Adolpho Varnhagen; "Tratado da Terra e Gente do Brasil", de Fernão Cardim; "Crônica do Brasil "História do Brasil", de Jonathas Serrano; "A Primeira História do Brasil: História da Província de Santa Cruz a que vulgarmente chamamos Brasil", de Pero de Magalhães de Gandavo; e "História da América Portuguesa", de Sebastião da Rocha Pitta. Essas obras são indiscutivelmente fontes imprescindíveis para os pesquisadores do Período Colonial brasileiro. Contudo, poucas apresentam o tema franciscano, e quando se referem à Ordem, fazem-no de forma superficial, apenas como uma referência.

Como se percebe, foram poucos os autores clássicos - aqui considerados aqueles cujo valor foi posto à prova pelo tempo e que, devido à sua originalidade, tornaram-se modelos autorizados ou abonados pelos demais historiadores - que se dedicaram à pesquisa sobre a Ordem franciscana no Brasil. Mais raros ainda são os trabalhos produzidos sobre a ação educativa dos franciscanos. Quando abordado, o tema é tratado em uma perspectiva ampla que não permite verificar a especificidade do fazer educativo da Ordem franciscana na sua ação missionário-catequética.

\section{FRANCISCANOS E A EDUCAÇÃO NO BRASIL}

São raros os trabalhos encontrados sobre os franciscanos e a educação no Brasil Colonial. Poucos autores e pesquisadores se dedicaram a investigar e escrever sobre o tema. A razão disso talvez esteja nas questões já apresentadas nos itens anteriores, o que, todavia, não justifica a escassez desses trabalhos; ao contrário, reforça a tese de que é preciso enfrentar o problema que se impõe aos estudiosos da história da educação brasileira a respeito das críticas endereçadas a esse campo de estudo, no que se refere à unanimidade estabelecida pela literatura educacional sobre a hegemonia jesuítica na educação Colonial.

Importante esclarecer que o objetivo desta parte da revisão é o levantamento de produções que abordam, especificamente, a ação educativa dos franciscanos no Período Colonial, excluindo, pois, os autores do campo da historiografia brasileira ou franciscana que escreveram sobre o tema.

$\mathrm{Na}$ pesquisa realizada foram encontrados dois textos - uma tese e um artigo - que abordam de forma especial, o tema: "franciscanos na educação brasileira". Eles serão apresentados de acordo com a ordem cronológica em que foram publicados.

Em 1961, Venâncio Willeke, grande estudioso dos franciscanos, escreveu um artigo

Revista HISTEDBR On-line, Campinas, n.43, p. 254-267, set2011 - ISSN: 1676-2584 
intitulado "Escolas Franciscanas do Brasil", que foi publicado na Revista da Escola de Belas Artes de Pernambuco, ano v, n. 1, p.87. O artigo discorre sobre as escolas franciscanas fundadas no Brasil após a instalação, em 1584, da Custódia de Santo Antonio do Brasil em Pernambuco, dependente da Província de Santo Antonio de Portugal.

O artigo de Venâncio Willeke é, com certeza, o trabalho que mais se aproxima de um estudo sobre a ação educativa dos franciscanos no Brasil. Podem-se encontrar outros trabalhos que se referem à "escola franciscana", mas trata-se do entendimento franciscano a respeito do complexo doutrinal sistematizado no século XIII pelos mestres eminentes da Ordem e, portanto, classificados como franciscanismo ou estudo da história e da filosofia mística da Ordem, não podendo ser confundidos com história da educação praticada pelos franciscanos.

Em 1974, Ailene Contreiras dos Santos desenvolveu, na Universidade Federal do Rio de Janeiro, uma tese de doutorado sobre os jesuítas e os franciscanos, intitulada "Estudo Documental da Atuação Jesuítica e Franciscana na Educação do Brasil - Colônia (1500-1808)".

Esses são os dois trabalhos que tomaram a educação praticada pela Ordem franciscana como objeto de estudo. Porém é preciso considerar aqui outras obras que, embora não tratem do tema como o objeto de suas análises, apresentam o assunto de forma especialmente ressaltada.

Em 1975, Alice Bertoli Arns, então professora de cultura brasileira na Faculdade de Filosofia, Ciências e Letras de Paranaguá, publicou um livro intitulado "Laguna: Uma Esquecida Epopéia de Franciscanos e Bandeirantes", prefaciado por Venâncio Willeke, no qual se narra a história religiosa e cultural nos primórdios da colonização do estado de Santa Catarina, enfatizando a ação missionária dos freis franciscanos espanhóis Bernardo de Armenta e Alonso Lebrón, em 1538 em Laguna ou Província de Jesus, como frei Bernardo denominou a Missão por ele ali estabelecida. ${ }^{12}$

Frei Venâncio Willeke, no prefácio do livro, assim se refere ao trabalho da autora:

A matéria tão magistralmente versada pela autora quanto a Mbyaçá e a Província de Jesus, deve encher de orgulho a todos os catarinenses. Pois, trata-se da primeira escola missionária do Brasil de que temos notícia certa. [...] Corroborando a veracidade de tudo quanto se refere à Missão franciscana de Mbyaçá, falam as fontes jesuíticas, coevas e insuspeitas por não defenderam a própria causa. (ARNS, 1975, p. 9)

A autora divide a história dos franciscanos em Santa Catarina em três ciclos: o "espanhol-platino", no primeiro século da colonização; o "ciclo luso-brasileiro", que se inicia com o estabelecimento da primeira Custódia portuguesa franciscana no Brasil, em 1659 , até a sua quase extinção em 1740; e o "atual ciclo", iniciado por franciscanos alemães, que vieram para a restauração da Província franciscana brasileira iniciada em $1889^{13}$.

Arns (1975) se dedica com mais afinco ao ciclo espanhol-platino, devido ao fato de que, por falta de delimitação geográfica mais precisa, para o qual só se possuía o tratado de Tordesilhas, a costa brasileira ao sul de Cananéia era um território de disputas. Entretanto, por ter sido parte da colonização da Bacia do Rio da Prata, empreendida pela Espanha, o sul do Brasil era considerado território mais hispânico que português. A colonização portuguesa na região sul só se efetivou a partir de 1640. Assim, a autora afirma: 
Apresenta-se uma correlação entre o domínio efetivo da Coroa portuguesa e a história da Ordem franciscana, que registra a presença de frades espanhóis no ciclo espanhol-platino, e só mais tarde, de frades luso-brasileiros, com o definitivo estabelecimento da Custódia e, posteriormente, da Província Franciscana da Imaculada Conceição do Brasil. [...] A presença do franciscano marca os primórdios da colonização meridional do Brasil, o que atesta a existência de armas da Ordem, verificadas nas primeiras vilas do Paraná, Santa Catarina e Rio Grande do Sul. Essas armas - o braço de Jesus sobreposto ao de São Francisco com a cruz ao meio - representam um dos poucos vestígios de uma atividade de conteúdo histórico de importância, uma vez que alcança a profundidade das primeiras origens da história deste sul do Brasil. (ARNS, 1975, p.17-18)

Luiz Fernando Conde Sangenis, que já foi apresentado neste texto em outra categoria, será aqui recobrado porque se propõe à análise da atuação educativa da Ordem franciscana no Brasil.

Ainda que dedicado ao tema, "franciscanos" na educação brasileira e localizado no Período Colonial, o livro não oferece maiores detalhes sobre o trabalho pedagógico desenvolvido pelos frades franciscanos. Dedica-se mais à historiografia brasileira e educacional em confronto com a historiografia franciscana, com ênfase na ação educativa da Ordem franciscana. Porém, apresenta uma boa revisão bibliográfica dos autores clássicos da literatura educacional brasileira em relação à ação educacional dos franciscanos no Brasil. O embate de Sangenis, mesmo que muito bem fundamentado em fontes primárias e secundárias, não consegue, na maioria das vezes, extrapolar as discussões já apresentadas por outros autores que se dedicaram ao tema, tendo, pois, gravitado em torno das mesmas questões já apresentadas pela bibliografia franciscana, notadamente a que se refere à primazia dos franciscanos como Ordem missionária no Brasil.

Entre as contribuições do trabalho de Sangenis, quer-se destacar a análise que o autor desenvolve e que denomina "produção dos silêncios", na qual procura entender o movimento concreto que gerou a pouca referência da historiografia brasileira ao trabalho missionário franciscano comparativamente aos jesuítas sobre os quais chega à seguinte conclusão:

Os jesuítas foram grandes produtores de documentos e hábeis em divulgá-los, lançando mão da nova e revolucionária tecnologia: Boa parte do que escreveram e publicaram tinha o objetivo de atingir o maior número de pessoas, a partir dos extratos mais influentes das sociedades européias. Ainda que utilizemos termos extemporâneos, os jesuítas, certamente, foram a primeira das organizações a perceber e utilizar eficazmente o grande poder da imprensa para influenciar a opinião pública a seu favor. Em especial, as cartas ânuas da Companhia, divulgadas aos quatro cantos da terra, tornaram-se um grande fenômeno de mídia a construir uma das primeiras campanhas propagandísticas dos tempos modernos. (SANGENIS, 2006, p.75)

As análises desenvolvidas pelo autor são interessantes, mas é necessário considerar outros fatores importantes que estavam envolvidos no contexto Colonial. Os conflitos entre as Ordens religiosas, franciscana e jesuítica durante a colonização do Brasil, e a produção

Revista HISTEDBR On-line, Campinas, n.43, p. 254-267, set2011 - ISSN: 1676-2584 263 
do silêncio historiográfico por meio da propaganda, por si sós, não explicam a hegemonia dos jesuítas na historiografia brasileira. Dessas relações não se pode prescindir outros interesses que estavam postos naquele momento histórico e nos quais a obra missionária estava inserida. A ação missionária fazia parte do projeto de expansão, no território americano, das nações européias. Não eram apenas disputas religiosas que estavam em jogo, mesmo porque se tratava de duas Ordens religiosas cristãs e católicas. O que se apresentava era a necessidade de afirmação das nações conquistadoras, inclusive da Santa Sé, no espaço conquistado.

Sangenis (2006), apesar de se referir à experiência dos missionários franciscanos espanhóis no Brasil, deixou, a exemplo de muitos outros historiadores, de considerar a presença espanhola na disputa pelo território brasileiro no Período Colonial, bem como a relação entre a Igreja e o Império, no que se refere ao domínio da ação missionária. Ao analisar o problema em nível conjuntural, reduziu a ausência historiográfica da ação franciscana à mera questão de disputas ideológico-religiosas, portanto, perdendo, de vista o seu significado estrutural. Outra questão a ser considerada é que no contexto português quinhentista, não é possível a dissociação entre os poderes espiritual e temporal. José Maria de Paiva esclarece o assunto quando afirma:

No contexto português quinhentista de unidade originária entre a fé e o poder político - este se identificando também com a direção dos negócios econômicos - compreende-se que a pregação da religião tenha feito parte de todo um conjunto de recursos usados para a consecução dos grandes objetivos assinalados pelo estamento dominante para a sociedade. Não se deve, com efeito, analisar o processo colonial como um empreendimento do comércio ao qual se tenha associado à Igreja, um em busca do ouro, a outra em busca das almas. O homem português, conscientemente uno pela instauração do reino dos céus neste tempo, não chegou ao uso da razão esclarecida e, por conseguinte, não soube dissociar o escatológico, do presente; o espiritual, do temporal; o religioso do econômico; a fé do império. (PAIVA, 2006, p. 95)

Assim como o português quinhentista possuía uma visão teocêntrica do mundo, também a possuíam todos os homens e nações européias envolvidas no processo de conquista ultramarina. Se, para Portugal, não havia diferenciação entre o poder temporal e o espiritual, também não o havia para a Espanha. Se, na literatura histórica brasileira, são poucos os trabalhos que se dedicaram a pesquisar a ação franciscana, também não foram muitos os que se dedicaram a analisar a colonização espanhola do Brasil.

Contar a história do primeiro século da presença européia nestas latitudes é, principalmente, trazer à luz a gesta dos espanhóis em nossa terra. [...] Há pouco mais de um século, as fronteiras meridionais da nação eram disputadas "a espada e a pata de cavalo", como ainda costumam dizer os descendentes dos guerreiros que ajudaram a desenhar o mapa do país. É compreensível, pois, o ranço ufanista dos diplomatas e intelectuais brasileiros do passado que, defendendo interesses geopolíticos, privaram os catarinenses de mais de um século de sua história colonial "varrendo-a para baixo do tapete". (MELLO, 2005, v. 1, p. 28)

Essa é uma questão fundamental a ser observada pelos historiadores, ao analisarem a história dos franciscanos no Brasil e, de maneira especial, pela historiografia

Revista HISTEDBR On-line, Campinas, n.43, p. 254-267, set2011 - ISSN: 1676-2584 264 
educacional. Muito antes dos jesuítas portugueses trabalharem a serviço da Coroa de Portugal, em nome da dilatação da fé do império, os franciscanos já o faziam em grande escala a serviço da Coroa espanhola para assegurar a dominação dos territórios conquistados.

Os cinco anos dedicados à pesquisa e materializados na tese que apresenta a especificidade educativa dos frades franciscanos da qual se originou esses três artigos sobre as fontes documentais franciscanas no Brasil Colonial, que se encerram com o presente texto, autoriza a afirmar que não há como entender a gênese do campo educacional brasileiro sem considerar a Ordem franciscana. Assim como não há como compreender a o trabalho evangelizador missionário e catequético desta Ordem sem considerá-la em relação com a Coroa espanhola e mais precisamente, com a Península Ibérica. São nessas relações que se encontram os condicionamentos que determinaram a configuração do campo educacional americano e, por conseguinte, brasileiro. Contudo, mais sério que isso, já que um decorre do outro, é admitir o desconhecimento de informações indispensáveis para a compreensão da história da educação brasileira. Há uma grande contradição entre a relevância da presença efetiva dos franciscanos na constituição e na participação da história educacional do país, como foi evidenciado pela tese, na qual este artigo se fundamenta, em relação à insignificante produção do campo historiográfico sobre o tema. Em razão disso, o trabalho de divulgação dos conhecimentos produzidos durante a pesquisa de doutorado, se impõe.

Contribuir para avançar os estudos nesse campo por meio divulgação de parte dos resultados obtidos na pesquisa foi objetivo desses três artigos que teve como intenção, diminuir a escassez de informações a respeito do assunto, bem como, acrescentar aos escassos trabalhos já produzidos, as informações que avançaram os conhecimentos já elaborados e fontes documentais que possam colaborar para seu alargamento.

Com os mesmos propósitos, pretende-se continuar o trabalho de publicação de materiais recolhidos em arquivos, bibliotecas e na própria Ordem franciscana durante a investigação realizada na Espanha, onde se encontrou fontes de pesquisa fundamentais para a ampliação do conhecimento a respeito do assunto, assim como para outros temas concentrados na história colonial da educação brasileira e da história do Brasil.

Referências:

ARNS, Alice Bertoli. Laguna: uma esquecida epopéia de franciscanos e bandeirantes, Paranaguá, 1975.

COLARES, Anselmo Alencar. Colonização, Catequese e Educação no Grão-Pará. Tese de Doutorado em Educação, Unicamp, 2003.

FREYRE, Gilberto. A Propósito dos Frades: Sugestões em Torno da Influência de Religiosos de São Francisco e de Outras Ordens Sobre o Desenvolvimento de Modernas Civilizações Cristãs, Especialmente das Hispânicas nos Trópicos. Salvador, Aguiar \& Souza, 1959.

KARNAL LEANDRO, Teatro da Fé. Representação religiosa no Brasil e no México do século XVI. São Paulo, Editora Hucitec, 1998, 253 pp., ISBN 85-271.0435-0.

Revista HISTEDBR On-line, Campinas, n.43, p. 254-267, set2011 - ISSN: 1676-2584 265 
LYRA, Sophia A. São Francisco de Assis e o Brasil. Rio de Janeiro: José Olympio, 1978.

MELLO, Amílcar D’Avila de. Expedições: Santa Catarina na Era dos Descobrimentos Geográficos. Florianópolis: Expressão, 2005. 3 v. ISBN 85-87887-03-3.

SANGENIS, Luiz Fernando Conde: Gênese do pensamento único em educação: Franciscanismo e Jesuitismo na História da educação brasileira. Petrópolis, Rio de Janeiro: Vozes, 2006.

SANTOS, Ailene Contreiras dos. Estudo Documental da Atuação Jesuítica e Franciscana na Educação do Brasil - Colônia (1500-1808), tese de doutorado: Universidade Federal do Rio de Janeiro, 1974.

WILLEKE, Venâncio. Escolas Franciscanas do Brasil. In: Revista da Escola de Belas Artes de Pernambuco. Recife, 1961.

Notas:

${ }^{1}$ Mestre em educação pela Universidade Estadual de Maringá - UEM, Doutora em educação pela Universidade Estadual de Campinas - UNICAMP, Pós-doutoranda na Universidade Estadual de Campinas UNICAMP. Membro do Grupo de Pesquisa História, Sociedade e Educação no Brasil -HISTEDBR.

${ }^{2}$ Revisão bibliográfica elaborada para a consecução da tese de doutorado intitulada: A experiência Educativa da Ordem Franciscana: Aplicação na América e sua Influência no Brasil Colonial, defendida na Unicamp em fevereiro de 2010 sob a orientação do prof. Dr. Dermeval Saviani, foi considerada por Frei Sandro da Costa, professor de história dos franciscanos no Brasil e atual diretor do Instituto Teológico Franciscano do Brasil, situado em de Petrópolis, a mais completa revisão da categoria elaborada até o momento.

${ }^{3}$ IGLESIAS, Tania Conceição. A Experiência Educativa da Ordem Franciscana: aplicação na América e sua influência no Brasil Colonial. Campinas, 2010. Tese (Doutorado em História e Filosofia da Educação) Universidade Estadual de Campinas (UNICAMP), Fevereiro de 2010.

${ }^{4}$ Em 1494, com a arbitragem do Vaticano, cosmógrafos espanhóis e portugueses deram ao mundo mais dois hemisférios. Com o meridiano que traçaram sobre o globo - a linha demarcatória de Tordesilhas -, as duas potências dividiram as suas esferas de influências: as terras a leste ficaram sob domínio português; a oeste, espanhol [...] Na América, ela passava sobre o Brasil: ao norte, na ilha de Marajó; ao sul, no território onde hoje se assenta o estado de Santa Catarina. (MELLO, 2005, v. 1, p.28)

5 Amílcar D’Avila de Mello, natural da fronteira sui generis Rivera-Livramento, é cidadão Brasileirouruguaio. Nasceu em 22 de julho de 1957, de mãe uruguaia e pai Brasileiro. Residiu até os 18 anos de idade em Rivera, Uruguai, onde iniciou seus estudos nas áreas antropológica e arqueológica com o Prof. Osmar Santos, renomado erudito daquele país. Estudou nos dois países. Em 1977, mudou-se para Porto Alegre, onde cursou História na Universidade Federal do Rio Grande do Sul. Incursionou profissionalmente nas áreas de aviação comercial e comércio exterior até fixar residência na Lagoa da Conceição, Florianópolis, em 1986. Na capital catarinense, realizou curso de pós-graduação, especialização em etnolinguística, na Universidade Federal de Santa Catarina. Atualmente, atua como tradutor e intérprete simultâneo de conferências nos idiomas inglês, espanhol e português. Paralelamente, realiza pesquisas históricas. É autor de diversos artigos e da obra monumental Expedições e Crônicas das Origens - Santa Catarina na Era dos Descobrimentos (1501-1600), Florianópolis: Ed. Expressão, 2005, 3 vol., 1.500p. Fruto de mais de dez anos de pesquisas no Brasil e no exterior, Expedições e Crônicas das Origens contém preciosas informações "garimpadas" nos acervos de diversas instituições, como o Arquivo Geral das Índias de Sevilha, divisões de obras raras das Bibliotecas Públicas de Londres, Nova York, Congresso Norte-americano, e da Universidade de Harvard. As fontes consultadas, em sua maioria primárias, são principalmente constituídas por diários de bordo, cartas régias, diplomáticas e privadas, além de relatórios, inquéritos e depoimentos de testemunhas envolvidas em

Revista HISTEDBR On-line, Campinas, n.43, p. 254-267, set2011 - ISSN: 1676-2584 266 
litígios. A cuidadosa seleção e articulação desses documentos oferecem ao leitor a oportunidade de conhecer a fascinante história da Santa Catarina quinhentista, narrada pelos seus protagonistas. (Fornecidos pelo autor).

${ }^{6}$ A entrevista concedida por Mello à "República do Livro", em 12 de setembro de 2006, encontra-se no site: <http://www.republicadolivro.com.br/info.php?not=10638\&oque=2>.

${ }^{7}$ Essas escolas teriam sido fundadas onde se encontra atualmente a cidade de Laguna que, na época, denominava-se Biaça. Segundo Mello, esse nome aparece na literatura com grafias diversas, mas trata-se do mesmo local: Biaça, Biaza, Viaça, Viasa, Enbiaça, Ibiaza, Ibiaça, Inbiassape, Ibuassup, Mbiaça, Mbiazá. Essas são algumas das denominações que a barra de Laguna dos Patos, a Laguna de hoje, recebeu ao longo do século XVI e cuja tradução, não obstante a grafia diversa dada pelos cronistas é barra, boca de rio ou barra do porto. (MELLO, 2005, v.3, p.62)

${ }^{8}$ A tal carta de Manuel da Nóbrega é abundantemente citada pelos historiadores, no entanto não encontramos a referência ao documento em nenhum desses trabalhos. Supõe-se que essa informação foi tirada de Jaboatão que a cita, mas não a referencia, e foi repassada como tal em outros trabalhos. Contudo, como resultado da presente investigação, a carta do jesuíta será devidamente referenciada.

${ }^{9}$ Luiz Fernando Conde Sangenis é Mestre e Doutor em educação pela Universidade Federal Fluminense, professor adjunto da Universidade Estadual do Rio de Janeiro. Atua na Faculdade de Formação de Professores e é coordenador do Curso de Pedagogia da Universidade Estácio de Sá do mesmo estado e autor de Gênese Do Pensamento Único Em Educação: Franciscanismo e Jesuitismo na História da educação Brasileira. Petrópolis: Vozes, 2006. p. 197.

${ }^{10} \mathrm{O}$ autor se refere às seguintes obras: Rupert, Arlindo. A Igreja no Brasil. V. III. Santa Maria: Palloti, 1981; Hoornaert, Eduardo et alii. História da Igreja no Brasil: ensaio de interpretação a partir do povo. Petrópolis: Vozes, 1983; Holanda, Sérgio Buarque. História Geral da Civilização Brasileira - Tomo I: A Época Colonial- v. 1: Do descobrimento à expansão territorial. 2. ed. São Paulo: Difusão Européia do Livro, 1963; Maria, Júlio. O Catolicismo no Brasil. Rio de janeiro: Agir, 1950; Colares, Anselmo Alencar. Colonização, Catequese e Educação no Grão Pará. Campinas: Unicamp, 2003.

11 O autor lista nessa categoria os seguintes trabalhos: Calmon, Pedro in Reis, Arthur César. Conquista Espiritual da Amazônia, São Paulo, 1943; Calmon, Pedro. História do Brasil, v. II. Rio de Janeiro: José Olympio, 1963; Guedes, Max Justo. A Relevância da ação Missionária na Expansão Geográfica do Brasil. In: Missionação Portuguesa e Encontros de Culturas, Braga, 1993; Hoornaert, Eduardo et alii. História da Igreja no Brasil: ensaio de interpretação a partir do povo. Petrópolis: Vozes, 1983; Abreu, Capistrano. Capítulos de História Colonial: 1500 - 1800. 4. ed. São Paulo: Sociedade Capistrano de Abreu/livraria Briguiet, 1954; Alves, Marcio Moreira. A Igreja e a Política no Brasil. Lisboa, 1977; Acosta, José de. De Procuranda Indorum Salute. Madrid: Consejo Superior de Investigaciones Cientificas, 1987. Airosa, Plínio. Apud Soares, José Carlos de Macedo. Santo Antonio, Militar do Brasil. Rio de Janeiro: 1942; Pombo, Rocha. História do Brasil. 11. ed. São Paulo: Melhoramentos, 1963.

${ }^{12}$ Província de Jesus - Bernardo de Armenta (1538). A primeira missão religiosa do sul do Brasil situava-se no lugar que fora a importante aldeia guarani - carijó do Viaça. Floresceu entre 1538 e 1548, período em que milhares de indígenas foram catequizados pelos freis Bernardo de Armenta e Alonso Lebrón. Em 1541, após a relação se deteriorar com os índios, a missão foi parcialmente abandonada. Foi revitalizada entre 1546 e 1548, ano em que sofreu um ataque de portugueses caçadores de índios. Em seu auge, devia ter no meio a Igreja e a casa dos frades franciscanos. A certa distância, nas duas casas de recolhimento eram isoladamente doutrinados as moças e os moços carijós. Espalhadas ao redor, havia as ocas dos índios e as casas dos espanhóis que, junto com os frades, dirigiram esse centro catequético. Estendendo-se por todos os lados, havia grandes roças... (MELLO, 2005, p. 57)

13 Sobre o estabelecimento, a extinção e restauração dos franciscanos no Brasil, consultar: Frei Basílio Röwer: A Ordem Franciscana no Brasil. Petrópolis: Vozes, 1942.

Recebido em: $\quad 19 / 11 / 10$

Aprovado em: $\quad 15 / 03 / 11$

Revista HISTEDBR On-line, Campinas, n.43, p. 254-267, set2011 - ISSN: 1676-2584 267 